\title{
Hubungan Nilai Ujian Try Out Lokal dengan Nilai Computer Based Test Uji Kompetensi Mahasiswa Program Profesi Dokter di Fakultas Kedokteran Universitas Sam Ratulangi Manado
}

\author{
${ }^{1}$ Atika I. S. Labatjo \\ ${ }^{2}$ Firginia P. Manoppo \\ ${ }^{2}$ Siemona L. E. Berhimpon
}
${ }^{1}$ Program Studi Pendidikan Dokter Fakultas Kedokteran Universitas Sam Ratulangi Manado
${ }^{2}$ Medical Education Unit Fakultas Kedokteran Universitas Sam Ratulangi
Email: atikalabatjo75@gmail.com

\begin{abstract}
The graduation rate of the Computer Based Test (CBT) in Competency Test for Medical Student Profession Program (UKMPPD) of Medical Faculty, Sam Ratulangi University is still below 50\% so far. Therefore, the Medical Faculty of Sam Ratulangi University makes various efforts to increase their graduation rate, inter alia implementation of local Try Out (TO) test as a filtering test required before the CBT UKMPPD. This study was aimed to find out whether there was a correlation between the local TO test score and the CBT UKMPPD score. This was a descriptive analytical study with a cross-sectional design. Data of this study were the local TO test score and the CBT UKMPPD score of the Medical Faculty of Sam Ratulangi University. The data were analyzed with the Spearman correlation test. The results showed that there was a significant correlation $(P=0.028)$ between the local TO test score and the CBT UKMPPD score with a very weak positive correlation value $(r=0.199)$. Conclusion: There was a significant correlation between the local TO test score and the CBT UKMPPD score.
\end{abstract}

Keywords: TO, CBT, UKMPPD

\begin{abstract}
Abstrak: Angka kelulusan Computer Based Test (CBT) Ujian Kompetensi Mahasiswa Program Profesi Dokter (UKMPPD) Fakultas Kedokteran Universitas Sam Ratulangi (FK Unsrat) Manado masih berada di bawah 50\%. Pihak FK Unsrat melakukan berbagai upaya agar angka kelulusan UKMPPD FK Unsrat meningkat, salah satunya yaitu dengan mengadakan ujian Try Out (TO) lokal sebagai ujian penyaring yang wajib diikuti sebelum CBT UKMPPD. Penelitian ini bertujuan untuk mengetahui apakah terdapat hubungan antara nilai ujian TO lokal dengan nilai CBT UKMPPD. Jenis penelitian ialah deskriptif analitik dengan ddesain potong lintang. Data penelitian ialah nilai ujian TO lokal dan CBT UKMPPD FK Unsrat. Data dianalisis menggunakan uji korelasi Spearman. Hasil penelitian mendapatkan hubungan bermakna $(P=0,028)$ antara nilai ujian TO lokal dengan nilai CBT dengan tingkat keeratan positif yang sangat lemah $(r=0,199)$. Simpulan: Terdapat hubungan bermakna antara nilai ujian TO lokal dengan nilai CBT UKMPPD.
\end{abstract}

Kata kunci: TO, CBT, UKMPPD

Pendidikan dokter adalah pendidikan yang diselenggarakan untuk menghasilkan dokter yang memiliki kompetensi untuk melaksanakan pelayanan kesehatan primer dan merupakan pendidikan kedokteran dasar sebagai pendidikan universitas. ${ }^{1}$
Dalam upaya penataan praktik kedokteran di Indonesia yang sebagaimana telah ditetapkan pada Undang-Undang (UU) nomor 29 tahun 2004 tentang Praktik Kedokteran, Komite Bersama (Komite Dokter Indonesia, Asosiasi Institusi 
Pendidikan Kedokteran Indonesia (AIPKI), Perhimpunan Dokter Keluarga dan sejumlah perangkat lainnya) menyepakati suatu bentuk uji kompetensi dalam rangka sertifikasi dokter lulusan baru Fakultas Kedokteran (FK) atau Program Studi Pendidikan Dokter (PSPD) yaitu Uji Kompetensi Dokter Indonesia (UKDI), yang sekarang dikenal dengan sebutan Uji Kompetensi Mahasiswa Program Profesi Dokter (UKMPPD). ${ }^{2}$

Di Indonesia sejak tahun 2013, menurut Surat Edaran Dirjen Pendidikan Tinggi Kementerian Pendidikan dan Kebudayaan nomor 88/E/DT/2013, UKMPPD digunakan sebagai exit exam meliputi Computer Based Test (CBT) dengan pertanyaan pilihan ganda (multiple choice questions) dan Objective Structured Clinical Examination (OSCE) untuk menguji attitude, knowledge, dan skills. ${ }^{1,3}$

Persentase kelulusan CBT UKMPPD (first taker dan retaker) FK Unsrat pada tahun 2017 periode Februari dan Mei masih di bawah dari $50 \%$ yaitu $40,8 \%$ dan $32 \%$ sedangkan angka kelulusan OSCE-nya yaitu $93,8 \%$ dan $76,6 \%{ }^{4}$

Pihak FK Unsrat melakukan berbagai upaya agar angka kelulusan CBT UKMPPD FK Unsrat meningkat, salah satunya yaitu dengan mengadakan ujian Try Out (TO) lokal sebagai ujian penyaring yang wajib diikuti sebelum CBT UKMPPD. Mahasiswa yang sudah menyelesaikan tahap program profesi dokter harus lulus dalam ujian TO lokal untuk bisa ikut serta dalam CBT UKMPPD.

Rendahnya tingkat kelulusan CBT UKMPPD di FK Unsrat dan penerapan ujian TO lokal tersebut menjadi dasar dalam penelitian ini. Tujuan penelitian ini ialah untuk mengetahui hubungan antara nilai ujian TO lokal dan nilai CBT UKMPPD.

\section{METODE PENELITIAN}

Jenis penelitian ini ialah deskriptif analitik dengan desain potong lintang. Teknik pengambilan sampel yang digunakan ialah total sampling. Dalam pengambilan sampel, karakteristik yang harus dipenuhi ialah mahasiswa yang baru pertama kali mengikuti CBT UKMPPD (peserta first taker).

Nilai TO lokal dan nilai CBT UKMPPD ialah variabel independen dalam penelitian ini. Keduanya digunakan sebagai indikator dalam menilai hasil belajar mahasiswa di FK Unsrat. Data penelitian dianalisis menggunakan uji korelasi Spearman karena setelah dilakukan uji normalitas didapatkan bahwa data kedua variabel tidak terdistribusi normal.

\section{HASIL PENELITIAN}

Jumlah mahasiswa FK Unsrat yang mengikuti UKMPPD periode Agustus dan November 2017 serta memenuhi kriteria inklusi pada penelitian ini berjumlah 122 orang. Tabel 1 memperlihatkan nilai rerata ujian TO lokal yaitu 75,73 dengan nilai terendah terendah 66,43 dan tertinggi 90,83. Rerata dari nilai CBT UKMPPD yaitu 67,62 dengan nilai CBT terendah yaitu 30,50 dan tertinggi 87,00.

Tabel 1 Distribusi nilai ujian TO lokal dan nilai CBT UKMPPD peserta first taker periode Agustus dan November 2017

\begin{tabular}{ccc}
\hline Nila ujian & $\mathbf{n}$ & $\begin{array}{c}\text { Mean } \\
\text { (Minimal-Maksimal) }\end{array}$ \\
\hline TO lokal & 122 & $75,73(66,43-90,83)$ \\
CBT & 122 & $67,62(30,50-87,00)$ \\
UKMPPD & & \\
\hline
\end{tabular}

Tabel 2 menampilkan bahwa mahasiswa yang dinyatakan lulus CBT UKMPPD periode Agustus dan November 2017 yaitu 80 orang $(65,6 \%)$ dan yang tidak lulus berjumlah 42 orang $(34,4 \%)$.

Tabel 2 Distribusi hasil CBT UKMPPD periode Agustus dan November 2017

\begin{tabular}{ccc}
\hline Hasil CBT & Jumlah & Persentase \\
\hline Lulus & 80 & 65,6 \\
Tidak lulus & 42 & 34,4 \\
\hline
\end{tabular}

Tabel 3 menampilkan hasil uji korelasi Spearman terhadap hubungan antara nilai ujian TO lokal dan nilai CBT UKMPPD mendapatkan nilai $P=0,028$. Selain itu, 
kekuatan korelasi antar kedua variabel sangat lemah $(r=0,199)$ dan berpola positif yang berarti semakin tinggi nilai TO lokal maka semakin tinggi pula nilai CBT UKMPPD.

Tabel 3. Analisis hubungan nilai ujian TO lokal dengan nilai CBT UKMPPD

\begin{tabular}{ccccc}
\hline & Mean & r & $\boldsymbol{P}$ & n \\
\hline Nilai TO & 75,73 & 0,199 & 0.028 & 122 \\
lokal & & & & \\
Nilai CBT & 67,62 & & & \\
UKMPPD & & & & \\
\hline
\end{tabular}

Uji korelasi Spearman

$\mathrm{r}=$ nilai korelasi; $P=$ nilai signifikansi; $\mathrm{n}=$ jumlah sampel

\section{BAHASAN}

Pada peneliutian ini, mahasiswa yang mengikuti CBT UKMPPD sebagai peserta first taker untuk periode Agustus dan November 2017 berjumlah 122 orang dengan rerata nilai ujian TO lokal yaitu 75,73 (Tabel 1). Rerata nilai ujian TO lokal tersebut sudah melampaui nilai batas lulus ujian untuk CBT UKMPPD yang telah ditetapkan $(66,00){ }^{3}$ sedangkan rerata nilai CBT UKMPPD yang didapatkan juga lebih tinggi daripada nilai batas lulus tersebut yaitu 67,62 (Tabel 1) tetapi bila dibandingkan dengan nilai rerata ujian TO lokal maka nilai rerata ujian TO lokal lebih tinggi daripada rerata nilai CBT UKMPPD. Hasil penelitian ini tidak sejalan dengan penelitian oleh Burhanudin dan Sutrisna ${ }^{5}$ di Fakultas Kedokteran Universitas Muhammadiyah Surakarta yang mendapatkan nilai rerata CBT $(80,50)$ lebih tinggi dibandingkan nilai rerata TO $(76,50)$ dengan jumlah sampel sebanyak 25 orang. Hal ini dapat terjadi karena nilai minimum ujian TO lokal tidak ada yang di bawah nilai batas lulus sedangkan nilai minimum CBT UKMPPD banyak yang berada di bawah nilai batas lulus (tidak lulus).

Fakultas Kedokteran Unsrat menggunakan ujian TO lokal sebagai penyaring untuk mahasiswa yang akan mengikuti CBT UKMPPD. Universitas yang menggunakan metode serupa untuk meningkatkan jumlah kelulusan UKMPPD ialah Univer- sitas Lampung yaitu dengan melakukan pembimbingan terpadu dan ujian TO sebelum menghadapi UKMPPD. ${ }^{6}$ Hasil ujian TO yang telah memenuhi standar yang ditentukan oleh kampus dijadikan sebagai prediksi kelulusan UKMPPD Nasional. ${ }^{7}$ Hal ini juga menjadi dasar FK Unsrat mengadakan ujian TO lokal yaitu selain sebagai alat untuk menyeleksi, juga untuk mengetahui sejauh mana kemampuan mahasiswa dalam menghadapi ujian CBT UKMPPD nantinya sehingga bisa meningkatkan persentase kelulusan peserta CBT UKMPPD FK Unsrat.

Ujian MCQ dengan metode CBT merupakan uji kompetensi dokter di Indonesia. Metode ini juga digunakan di berbagai negara di dunia, sebagai contoh National Board of Medical Examiners (NBME) di Amerika Serikat. ${ }^{8,9}$ CBT UKMPPD sendiri merupakan ujian yang dilaksanakan dengan menggunakan bantuan komputer sebagai alat untuk peserta mengerjakan soal ujian kompetensi. Ujian TO lokal yang dilaksanakan FK Unsrat juga menggunakan metode MCQ sama seperti pada ujian CBT UKMPPD dengan harapan mahasiswa mendapatkan gambaran dalam menghadapi ujian kompetensi yang sebenarnya. Perbedaannya yaitu ujian TO lokal yang dilaksanakan oleh FK Unsrat masih menggunakan metode paper based test, sehingga bisa saja terjadi kecurangan yang dilakukan oleh peserta ujian TO lokal agar dapat lulus yang bisa mengakibatkan terjadinya bias dalam hasil ujian TO lokal ini.

Pada Tabel 2 dapat dilihat persentase kelulusan peserta first taker pada CBT UKMPPD periode Agustus dan November 2017 di FK Unsrat ialah 65,6\%. Dikatakan bahwa faktor yang memengaruhi kelulusan uji kompetensi yaitu faktor internal berupa kemampuan akademik dan skills, kesehatan dan kepercayaan diri mahasiswa, dan faktor eksternal berupa kualitas pendidikan yang dilalui, pengalaman praktik, dan lingkungan wahana praktik yang mendukung serta proses bimbingan yang tepat. ${ }^{9}$ Dari acuan teori dilihat bahwa ujian TO lokal FK Unsrat termasuk dalam faktor eksternal 
yang dijelaskan di atas yaitu proses bimbingan yang tepat. Walaupun demikian, masih banyak faktor-faktor lain yang dapat memengaruhi hasil kelulusan dalam ujian kompetensi, sehingga faktor bimbingan saja tidak bisa menjadi satu-satunya hal yang menentukan apakah peserta ujian akan lulus atau tidak.

Data kelulusan peserta first taker UKMPPD nasional tahun 2014-2017 ialah 73\%. Jumlah peserta UKMPPD meningkat setiap tahun diikuti dengan peningkatan persentase kelulusan tiap tahunnya. Fakultas Kedokteran Unsrat berada di peringkat ke-8 di daftar universitas dengan persentase kelulusan UKMPPD $<50 \%$ dengan persentase kelulusan sebesar 49,2\% untuk peserta first taker. Dari 8 perguruan tinggi yang masuk dalam daftar tersebut hanya FK Unsrat yang berakreditasi A. Dalam data tersebut juga dicantumkan FK dengan angka kelulusan tertinggi yaitu Universitas Gadjah Mada dengan persentase kelulusan first taker sebesar 93,8\%. ${ }^{10}$ Selain itu, juga didapatkan angka kelulusan UKMPPD di Fakultas Kedokteran Universitas Muhammadiyah Sumatera Utara pada periode Agustus 2014 sampai Agustus 2015 yaitu $47 \%$ yang terdiri dari 32 peserta UKMPPD first taker. Di Fakultas Kedokteran Universitas Lampung yang lulus UKMPPD first taker pada periode November 2014 sampai Agustus 2015 ialah 76,2\% yang diikuti oleh 101 peserta UKMPPD first taker. $^{2}$ Terdapat pula data yang menyatakan bahwa kelulusan first taker UKMPPD selama tahun 2015 ialah sekitar $70 \%$ untuk CBT dan 90\% untuk OSCE. ${ }^{11}$ Angka kelulusan CBT FK Unsrat (first taker dan retaker) periode Februari dan Mei 2017 yaitu 40,8\% dan 32\%, sedangkan untuk OSCE yaitu $93,8 \%$ dan $76,6 \%{ }^{4}$ Angka kelulusan CBT UKMPPD FK Unsrat untuk periode Agustus dan November 2017 sendiri sudah lebih dari $50 \%$ yaitu untuk kedua periode tersebut sebesar $65,6 \%$ dari 122 orang peserta first taker, akan tetapi jumlah tersebut belum bisa berpengaruh besar dalam meningkatkan angka kelulusan UKMPPD. Apabila angka kelulusan CBT UKMPPD FK Unsrat sama dengan persentase kelulusan OSCEnya maka angka kelulusan UKMPPD pasti akan membaik, karena berdasarkan data di atas didapatkan bahwa penyebab angka kelulusan UKMPPD FK Unsrat masih tergolong rendah ialah angka kelulusan CBT yang lebih rendah daripada kelulusan OSCE.

Pada analisis korelasi antara nilai TO lokal dan nilai CBT UKMPPD didapatkan bahwa terdapat hubungan bermakna $(P=0,028)$ dengan tingkat keeratan yang sangat lemah dan arah korelasinya positif. Hal ini sejalan dengan penelitian oleh Burhanudin dan Sutrisna ${ }^{5}$ yang mendapatkan bahwa terdapat korelasi bermakna antara nilai TO dan nilai CBT UKMPPD dengan arah korelasi positif yang berarti semakin tinggi nilai TO, semakin tinggi nilai CBT UKMPPD dengan kekuatan korelasi yang sangat kuat. Hasil penelitian oleh Abdillah $^{12}$ juga menunjukkan bahwa terdapat hubungan positif dan bermakna antara TO terhadap kelulusan UKNI pada mahasiswa STIKES Ngudia Husada Madura. Dikatakan bahwa mahasiswa yang telah mengikuti TO akan lebih siap dalam mengerjakan soal ujian karena telah mempunyai gambaran tipe soal serta lebih tenang dalam proses pengerjaannya sehingga hasilnya akan lebih baik daripada mahasiswa yang tidak mengikuti TO. Pada penelitian ini hanya didapatkan korelasi yang sangat lemah antara nilai TO lokal dan nilai CBT UKMPPD. Dibandingkan dengan penelitian Burhanudin dan Sutrisna $^{5}$ dengan peserta yang akan mengikuti CBT UKMPPD telah mendapatkan bimbingan sebelum ujian TO dan setelah ujian TO terpisah dengan bimbingan untuk OSCE. Perbedaan hasil ini juga dapat disebabkan oleh beberapa hal lain yaitu faktor perbedaan standar soal yang digunakan dalam ujian TO lokal dan ujian CBT UKMPPD.

Hasil penelitian ini mendapatkan adanya hubungan antara ujian TO lokal dan CBT UKMPPD dengan tingkat keeratan yang sangat lemah dan berarah positif. Tingkat keeratan yang sangat lemah mungkin disebabkan karena standar soal 
TO lokal (validitas soal) FK Unsrat belum sepenuhnya mengikuti kaidah dan standar CBT UKMPPD yang sudah ditetapkan baik dalam hal tipe soal, struktur soal, jumlah soal, waktu pengerjaan, dan materi yang diujikan karena belum melewati proses review di tingkat nasional.

Penelitian ini merupakan penelitian pertama di FK Unsrat yang membahas tentang hubungan ujian TO lokal dengan CBT UKMPPD. Selain itu penelitian tentang TO juga masih sangat kurang kepustakaannya sehingga penelitian ini dapat digunakan sebagai dasar untuk mengembangkan penelitian selanjutnya yang berkaitan dengan variabel yang diteliti.

Limitasi penelitian ini ialah sampel yang digunakan terbatas, validitas soal ujian TO lokal dan CBT UKMPPD berbeda, dan terdapat perbedaan standard setting untuk penentuan nilai batas lulus ujian TO lokal dan CBT UKMPPD.

\section{SIMPULAN}

Berdasarkan hasil penelitian ini dapat disimpulkan bahwa terdapat hubungan bermakna antara nilai TO lokal dan nilai CBT UKMPPD dengan kekuatan korelasi sangat lemah dan arah korelasi positif yaitu semakin tinggi nilai TO maka akan semakin tinggi pula nilai CBT UKMPPD.

\section{SARAN}

Disarankan untuk penelitian lanjut dengan menggunakan jumlah sampel yang lebih besar dan variabel independen lainnya seperti nilai TO nasional karena standar soalnya sama dengan CBT UKMPPD. Selain itu, disarankan juga untuk memperbanyak penelitian tentang UKMPPD baik untuk CBT maupun OSCE dikarenakan acuan pustaka yang masih sangat kurang.

\section{DAFTAR PUSTAKA}

1. Konsil Kedokteran Indonesia. Standar Pendidikan Profesi Dokter Indonesia. Jakarta: Konsil Kedokteran Indonesia; 2012.

2. Puspitasari AYY. Korelasi indeks prestasi kumulatif mahasiswa terhadap kelulusan Uji Kompetensi Mahasiswa Program Profesi Dokter Periode November 2014-Agustus 2015 Fakultas Kedokteran Universitas Lampung [Skripsi]. Bandar Lampung: Universitas Lampung; 2014.

3. Direktorat Jenderal Pendidikan Tinggi Kementerian Pendidikan dan Kebudayaan. Mengenal Sistem Penjaminan Mutu Pendidikan Tinggi Kesehatan [Buku Saku]. Health Professional Education Quality (HPEQ) Project. 2013;1: 48-9.

4. PNUKMPPD. Daftar nilai hasil ujian periode 2015, 2016, 2017. [cited 2017 July 10]. Available from: https://mail.google. $\mathrm{com} / \mathrm{mail} / \mathrm{u} / \mathrm{0} / \mathrm{tab}=\mathrm{wm} \#$ search/DR+BI LLY/15d2a4c47ec4855d?projector=1.

5. Burhanudin I, Sutrisna EM. Evaluasi ujian seleksi masuk FK UMS dan Try Out UKMPPD berdasar validitas prediktif. Prosiding Annual Meeting Asosiasi Pendidikan Kedokteran dan Kesehatan Muhammadiyah ke-V. Palembang: Universitas Muhammadiyah Palembang. Available from: http://ejournal. umm.ac.id/index.php/sainmed/article/vi ew/5553.

6. Masnur M. Pengaruh kehadiran peserta selama bimbingan terhadap kelulusan UKDI [Skripsi]. Medan: Universitas Sumatera Utara; 2014.

7. Lisiswanti R, Sukohar A, Sari MI, Oktaria D. Korelasi ujian kompetensi lokal dan ujian kompetensi nasional mahasiswa Program Studi Pendidikan Dokter Universitas Lampung. Lampung: Universitas Lampung; 2016. Available from: http://repository.lppm.unila.ac.id/ 2161/1/FK\%20Unila\%2C\%20Revised $\% 20 f u l l t e x t \% 209$ th\%20Jakmed.pdf.

8. Norcini JJ, Mc Kinley. Assessment methods in medical education. Teaching and Teacher Education. 2007:23;239-50.

9. Pitono AJ, Istianah. Nilai Try Out sebagai prediktor hasil Uji Kompetensi Nasional Lulusan Ners STIKES Rajawali Bandung. Prosiding Seminar Nasional \& Lokakarya Uji Kompetensi Tenaga Kesehatan. LPUK-NAKES \&UN-PAD; ISBN No. 978-02-144227-2, 2016; p. 137.

10. RISTEKDIKTI. Potret Pendidikan Kedokteran di Indonesia: Refleksi upaya penjaminan mutu. 2018 [cited 11 Maret 2018]. Available from: http://www. 
54 Jurnal e-Biomedik (eBm), Volume 7, Nomor 1, Januari-Juni 2019

kopertis12.or.id/wpcontent/uploads/201 8/08/potret-pendidikan-kedokteranindonesia-2018-pptx-2.pdf.

11. Direktorat Jenderal Pendidikan Tinggi Kementerian Pendidikan dan Kebudayaan. Mengenal Sistem Penjaminan Mutu Pendidikan Tinggi Kesehatan
[Buku Saku]. Health Professional Education Quality (HPEQ) Project 2013;1:48-9.

12. Abdillah A. Analisis faktor-faktor yang mempengaruhi kelulusan Uji Kompetensi Ners Indonesia. Jurnal Penelitian Administrasi Publik. 2016;2(2):373-80. 